\title{
Optimal tread design for agricultural lug tires determined through failure analysis
}

\author{
Hyun Seok Song, ${ }^{1}$ Kyung Seok Sim, ${ }^{1}$ Tae Won Park² \\ ${ }^{1}$ Korea Automotive Technology Institute, Cheonan-si; ${ }^{2}$ Department of Mechanical Engineering, Ajou University, Suwon-Si, Korea
}

\begin{abstract}
Agricultural lug tires, commonly used in tractors, must provide safe and stable support for the body of the vehicle and bear any additional load while effectively traversing rough, poor-quality ground surfaces. Many agricultural lug tires fail unexpectedly. In this study, we optimised and validated a tread design for agricultural lug tires intended to increase their durability using failure analysis. Specifically, we identified tire failure modes using indoor driving tests and failure mode effects analysis. Next, we developed a threedimensional tire model using the Ogden material model and finite element method. Using sensitivity analysis and response surface methodology, we optimised the tread design. Finally, we evaluated the durability of the new design using a tire prototype and drum test equipment. Results indicated that the optimised tread design decreased the tire tread stress by $16 \%$ and increased its time until cracking by $38 \%$ compared to conventional agricultural lug tires.
\end{abstract}

\section{Introduction}

Agricultural equipment tires are often classified as tractor drive wheel tires, tractor steering wheel tires, forestry tires, and implement tires [available from The European Tyre and Rim Technical Organisation (ETRTO), Brussels, Belgium: http://www.etrto.org]. Agricultural tires have various roles such as traction, field and road transport, vibration transmission, noise

Correspondence: Tae Won Park, Department of Mechanical Engineering, Ajou University, Suwon-Si, 16499, Korea.

E-mail: park@ajou.ac.kr

Key words: Agricultural tire; central composite design; contact analysis; finite element method; optimisation; response surface method; tire tread design.

Acknowledgements: this research was supported by the South Korean Defense Acquisition Program Administration (UD150042AD).

Received for publication: 2 March 2017.

Accepted for publication: 11 August 2017.

CCopyright H.S. Song et al., 2018

Licensee PAGEPress, Italy

Journal of Agricultural Engineering 2018; XLIX:685

doi:10.4081/jae.2018.685

This article is distributed under the terms of the Creative Commons Attribution Noncommercial License (by-nc 4.0) which permits any noncommercial use, distribution, and reproduction in any medium, provided the original author(s) and source are credited. emission, load performance, and soil compaction. Agricultural lug tires, commonly used in tractors, must provide safe and stable support for the body of the vehicle. While driving on farmland and roads, many agricultural lug tires are prone to the following failures: premature lug wear, crack in the lug root, and side wall rupture. Prior agricultural tire studies have largely focused on the frictional traction between the tires and soil (Bailey et al., 1996; Way et al., 2009), as well as the development of tire analysis models. Nankali et al. (2012) examined tire tread stress using a two-dimensional finite element method (FEM) model. Biris et al. (2011) investigated changes in agricultural tire pressure in a static state. Roth et al. (2012) performed an empirical study to determine the normal stress at the agricultural tire tread. Static analysis is prevalent in prior agricultural tire studies. Some studies (Mohsenimanesh et al., 2009; Olmstead and Fischer, 2009) have also considered pressure distribution of the tire. Few subsequent studies have focused on the design of agricultural tires based on these analytical or empirical findings.

In addition, few studies have applied optimisation methods, such as response surface methodology (RSM), to improve agricultural tire designs. RSM supports concurrent evaluation of several design variables by minimising their repeated analysis. First proposed in the 1950s by Box and Wilson (1951) in the field of statistics, RSM has since been widely applied in a variety of fields (Bas and Boyaci, 2007; Bezerra et al., 2008). Craig et al. (2005) optimised collision safety by applying RSM in a vehicle model. To increase ride comfort from run-flat tires, Choi and Kang (2015) optimised the sidewall shape of a run-flat tire using RSM. To maximise the service life of a non-pneumatic semi-solid design, Roux et al. (1999) optimised the semi-solid tire using RSM.

In this study, we optimised and validated a tread design for agricultural lug tires intended to reduce the stress concentration at the tread and increase the durability of a tire using failure analysis. Specifically, we identified tire failure modes using indoor driving tests and failure mode effects analysis (FMEA). Next, we developed a three-dimensional (3D) tire model using the Ogden material model and FEM. Using sensitivity analysis, RSM, and establishing the tread shape as a design variable, we optimised the tread design. Finally, we evaluated the durability of this new design using a tire prototype and drum test equipment with the intent of validating the approach proposed in this study.

\section{Materials and methods}

\section{Tire failure mode identification}

Rausand and Hoyland (2004) define failure as the termination of the ability of an item to perform a required function. Failure can be classified according to usage as early failure caused by defects in design and manufacturing, random failure caused by overload or human error, or wear out failure caused by the degradation of materials and components. Failure can also be classified as physi- 
cal failure or chemical failure. In this study, we considered the random failure mode attributable to overload and physical failure mode. A common type of physical failure results from the stress concentration at the tire tread caused by the load of the vehicle and tire deformation that occurs during vehicle operation. This physical failure manifests itself as cracks in the tread. To fully investigate the failure modes of agricultural lug tires, we conducted indoor driving tests and FMEA. The indoor driving tests were performed using the drum test equipment capable of evaluating both passenger car and agricultural tires with a maximum speed of 4000 rpm and a maximum load of $12,000 \mathrm{~N}$. This equipment supports a tire slip and camber angle of up to $10^{\circ}$ and $5^{\circ}$, respectively. Figure 1 depicts the drum test equipment used in the indoor driving tests. The tire used in this study is a tractor front tire, the standard is 816 4PR HS605, the outside diameter is $789 \mathrm{~mm}$, and the sectional width is $191 \mathrm{~mm}$. The air pressure was $1.6 \mathrm{~kg} / \mathrm{cm}^{2}$, and the dynamic radius was $366 \mathrm{~mm}$. The number of lugs was 13 ea and the lug height was $29.5 \mathrm{~mm}$. To reproduce typical agricultural lug tire failures, load and operating speed conditions commonly used in the field were applied in this study. During the indoor driving tests, a load of $508 \mathrm{kgf}$ (reflecting a tractor with a fully loaded bucket) and a maximum speed of $20 \mathrm{kph}$ were used.

\section{Tire model development}

Following the identification of potential tire failure modes, a 3D tire model was developed using the Ogden material model and FEM. During the modeling process, four tire components were considered: i) tread; ii) carcass; iii) sidewall; and iv) bead wire. The road model was assumed to be a rigid body model in the indoor driving tests. Figure 2 depicts a typical agricultural lug tire and each of these tire components.

\section{Ogden material model}

The Ogden material model (Rausand and Hoyland, 2004) can be used to reflect the physical properties of hyperelastic materials in an incompressible model. Thus, it can be used to effectively estimate the strain rate in agricultural lug tires. The Ogden material model is formulated as follows:

$W\left(\lambda_{1}, \lambda_{2}, \lambda_{3}\right)=\sum_{p=1}^{N} \frac{\mu_{p}}{\alpha_{p}}\left(\lambda_{1}^{\alpha_{p}}+\lambda_{2}^{\alpha_{p}}+\lambda_{3}^{\alpha_{p}}-3\right)$

where $W$ is the tensile strength of a rubber material; $\lambda_{i}$ is the stretch ratio (ratio of the initial length to post-tension length of a material); $\alpha_{p}$ and $\mu_{p}$ are material constants, and $N=3$. Table 1 lists the material constant values used in this study for the tire tread and sidewall models. The carcass model consisted of orthotropic composites; however, nonlinear characteristics of these unidirectional materials were applied to simplify the modeling process. In addition, the bead wire model assumed a carbon steel content that exhibited insignificant strain.

\section{Finite element method}

To support FEM modeling in this study, the commercial software, ABAQUS, was used. Boundary conditions were determined in three steps: i) inflate the tire with air to determine tire pressure; ii)

Table 1. Tread and sidewall constants for the Ogden material model.

\begin{tabular}{lcccccc} 
& $\mu_{1}$ & $\alpha_{1}$ & $\mu_{2}$ & $\alpha_{2}$ & $\mu_{3}$ & $\alpha_{3}$ \\
Tread & -78.57 & 0.71 & 40.11 & 1.28 & 40.87 & -0.28 \\
Sidewall & -1122.70 & -5.67 & 632.80 & -4.82 & 515.22 & -9.01 \\
\hline
\end{tabular}

apply the vehicle load to an axle node to determine tread-road contact; and iii) apply the rotational angular velocity to the axle node to determine tire rotation. Input conditions for each of these steps are as follow. Tire inflation is $0.16 \mathrm{MPa}$. Load condition is $4660 \mathrm{~N}$ and Tire angular velocity is $7.27 \mathrm{rad} / \mathrm{s}$. Figure 3 shows the simplified shape models for each of these tire components and the boundary conditions and application times for each of these steps.

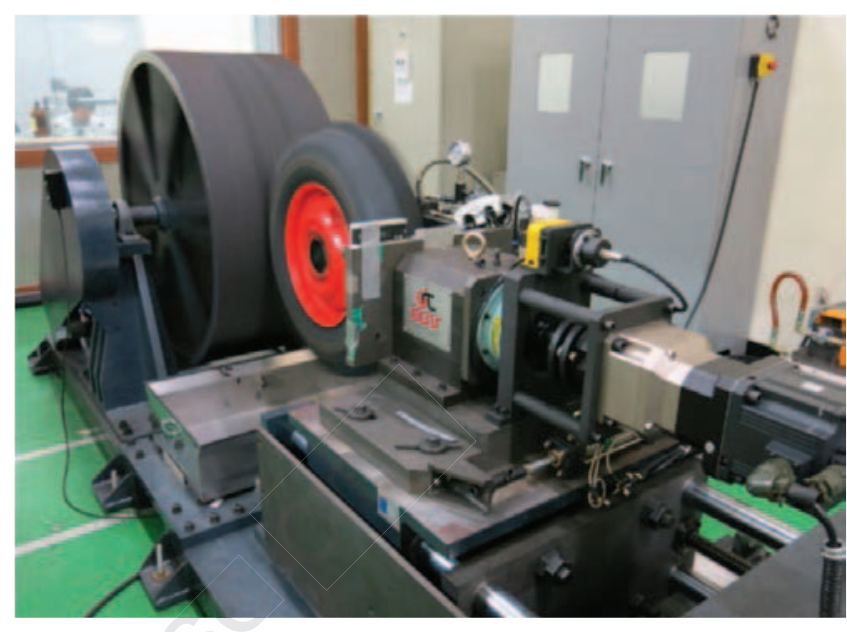

Figure 1. Drum test equipment used in the indoor driving tests.
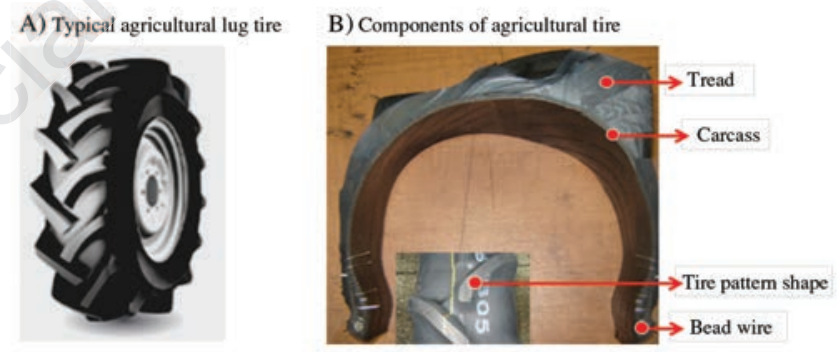

Figure 2. A) Agricultural lug tire and B) its components.

\section{A) Simplified shape models for tire components}

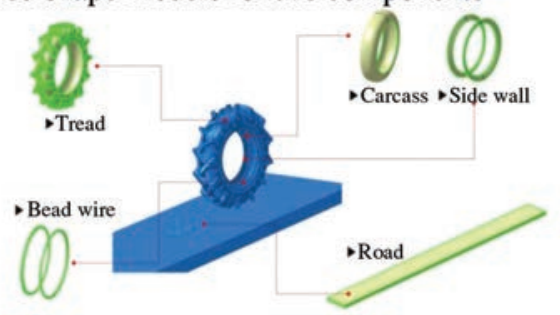

B) Boundary conditions and step input conditions

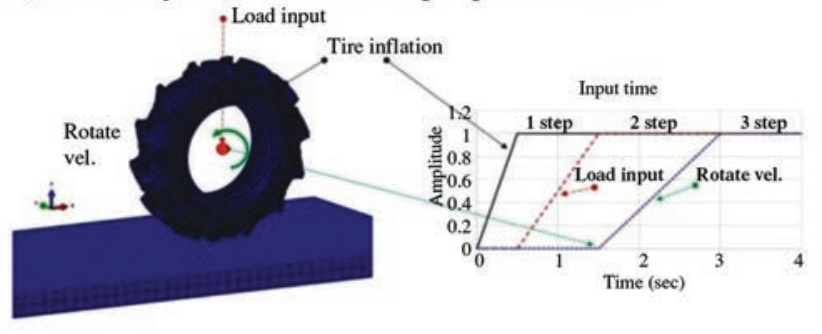

Figure 3. A) Simplified tire component models and B) FE analysis conditions. 


\section{Tread design optimisation}

Tire height, inclination, wear and load are the design variables of agricultural equipment tires. The tire height is designed based on the tire design standard [ETRTO or The Japan Automobile Tyre Manufacturers Association, Inc. (JATMA), Tokyo, Japan; or The Tire and Rim Association, Inc. (TRA), Copley, OH, USA], and the more the height, the more advantageous it is in that the tire can be used for a long time. Wear and load are excluded in this research, as wear related to the tire material and tire load is dependent on air pressure and the nylon cord number inside the tire. As part of the focus of this study is the cracks in the tread root of the tire, the relevant design items are the tread inclination and the edge round length of the tread block, as given in Table 2. The design variables were determined through careful review with tire developers. If we increase the tread inclination and the edge round length of tread block, the rigidity of the tire improves, but we can only see the disadvantages with respect to weight and cost. To reduce the stress concentration at the tread and prevent tire failure through cracking, we used sensitivity analysis and RSM to optimise the tread design variables.

\section{Sensitivity analysis}

Following a Plackett-Burman experimental design format, six design variables $\left(D V_{l}-D V_{6}\right)$ were selected for analysis based on the block angle of the tread and tread round, which are determined when stress is concentrated at the tread block. Figure 4 shows the three measurement locations on the tread block and the location of the block angle and round.

The maximum stress concentrated at the tread block was selected as an objective function. Minimum and maximum values (designated as -1 and +1 , respectively) were considered for each of the six design variables, based on a range of practical application. Table 2 lists the minimum and maximum values for each of the six design variables considered in this study.

The maximum stress measured at the tire tread for different design variable values was expressed as a response function using linear regression as follows:

$$
\begin{aligned}
& y=2.2289-0.0069 D V_{1}+0.0696 D V_{2}- \\
& 0.0354 D V_{3}-0.0787 D V_{4}-0.0276 D V_{5}-0.1101 D V_{6}
\end{aligned}
$$

where $y$ is the maximum stress measured at the tire tread, and $D V_{1^{-}}$ $D V_{6}$ are the design variables.

\section{Response surface method}

Following the sensitivity analysis, RSM (Ogden, 1984) was used to explicitly determine the optimal agricultural lug tire tread design. This method is typically used to derive functions based on experimental data. Recently, it has also been used to relate experimental factors and response values numerically derived as explicit functions.

The RSM includes a series of processes through which function coefficients are estimated using the method of least squares and a response surface model is subsequently obtained. The function coefficients are estimated based on measured data and a correlation between the design variable and response function. In this study, the following second-order response surface model was used:

$$
y=\beta_{0}+\sum_{i=1}^{n} \beta_{i} D V_{i}+\sum_{i=1}^{n} \beta_{i i} D V_{i}^{2}+\sum_{i=1}^{n} \sum_{j=i}^{n} \beta_{i j} D V_{i} D V_{j}
$$

where $\beta_{0}, \beta_{i}, \beta_{i i}$, and $\beta_{i j}$ are coefficients estimated using the least squares method, $D V$ is a design variable, and $n$ is the number of design variables considered.

The least squares method minimises the sum of residual squares as follows:

$$
\beta=\left(\mathbf{X}^{\mathrm{T}} \mathbf{X}\right)^{-1} \mathbf{X}^{\mathrm{T}} \mathbf{Y}
$$

where $X$ and $Y$ are matrices based on experimental and analytical data, respectively.

\section{Optimisation}

Based on the sensitivity analysis results (described later in Sensitivity analysis section), the number of design variables con-

Table 2. Minimum and maximum design variable values at each measurement location.

\begin{tabular}{lllcc}
$\begin{array}{l}\text { Thead block } \\
\text { component }\end{array}$ & $\begin{array}{c}\text { Design variable } \\
\text { value }\end{array}$ & \multicolumn{2}{c}{$\begin{array}{c}\text { Design variable } \\
\text { Min }(-1)\end{array}$} & Max $(+1)$ \\
\hline 1 & Angle $\left(^{\circ}\right)$ & $D V_{1}$ & 12 & 28 \\
& Round (mm) & $D V_{2}$ & 15 & 35 \\
2 & Angle $\left({ }^{\circ}\right)$ & $D V_{3}$ & 12 & 28 \\
& Round $(\mathrm{mm})$ & $D V_{4}$ & 15 & 35 \\
\hline 3 & Angle $\left(^{\circ}\right)$ & $D V_{5}$ & 6 & 14 \\
& Round $(\mathrm{mm})$ & $D V_{6}$ & 15 & 35
\end{tabular}

Table 3. Minimum, median, and maximum design variable values for optimisation.

\begin{tabular}{lccc} 
Design variable & \multicolumn{3}{c}{ Design variable value } \\
& Min $(-1)$ & Current $(0)$ & Max $(+1)$ \\
$D V_{2}$ & 10 & 25 & 40 \\
$D V_{4}$ & 10 & 25 & 40 \\
\hline$D V_{6}$ & 10 & 25 & 40 \\
\hline
\end{tabular}

Table 4. Central composite experimental design structure for optimisation.

\begin{tabular}{lccc} 
Scenario & $D V_{2}$ & $D V_{4}$ & $D V_{6}$ \\
1 & -1 & -1 & -1 \\
2 & +1 & -1 & -1 \\
\hline 3 & -1 & +1 & -1 \\
4 & +1 & +1 & -1 \\
\hline 5 & -1 & -1 & +1 \\
6 & +1 & -1 & +1 \\
\hline 7 & -1 & +1 & +1 \\
8 & +1 & +1 & +1 \\
\hline 9 & -1.216 & 0 & 0 \\
10 & +1.216 & 0 & 0 \\
\hline 11 & 0 & -1.216 & 0 \\
12 & 0 & +1.216 & 0 \\
\hline 13 & 0 & 0 & -1.216 \\
14 & 0 & 0 & +1.216 \\
\hline 15 & 0 & 0 & 0 \\
\hline
\end{tabular}


sidered for tread optimisation was reduced to three, with $D V_{2}, D V_{4}$, and $D V_{6}$ representing the tread block rounds. Table 3 lists the minimum, current, and maximum values used during optimisation. The commercial statistical software, Minitab, was used to support optimisation calculations (Box and Draper, 1987).

Central composite experimental design methods were applied to estimate the second-order response surface model considered in this study. Table 4 summarises the design structure, with the minimum, current, and maximum values designated as $-1,0$, and +1 , respectively. A value of \pm 1.216 (interpolated from minimum and maximum values) was applied when the number of central points was \pm 1 .

\section{Tread design validation}

To validate the approach proposed in this study, we lastly evaluated the durability of the optimised tread design using a tire prototype and drum test equipment.

The same equipment used previously for the indoor driving tests to identify tire failure modes was used again to validate the optimised tread design. Load and operating speed conditions of $508 \mathrm{kgf}$ and $20 \mathrm{kph}$ were again applied. The air pressure was set to $1.6 \mathrm{kgf} / \mathrm{cm}^{2}$ to comply with design conditions.

\section{Results}

In this study, we identified agricultural lug tire failure modes, developed a 3D tire model, optimised tread design, and evaluated the durability of the new tread design using a tire prototype. The results from these efforts follow.

\section{Failure modes}

Agricultural lug tire failure modes included cracking and tread abrasion where tread deformation occurs. The FMEA indicated that the occurrence of cracking was affected by a combination of the tread design and its physical properties. Comparatively, the occurrence of tread abrasion was affected primarily by the physical properties of the tread. Thus, the remainder of this study focused on reducing cracking in the area of tread deformation.

Results from the indoor driving tests indicated the occurrence of fine cracking at the edge of the tread after approximately $568 \mathrm{~h}$ of operation. Figure 5A and B compares the observed failure during our driving tests with an observed failure in practice.

On comparing the results of the in-practice vehicle test and the indoor driving test, it was observed that failure occurred similarly in both case at the lug root, and it was concluded that the same failure mechanism was present in the process of repeated lug folding, owing to the load generated during the running of the tire. The results of both tests can be analysed with the same mechanism.

\section{Tire model validation}

Prior to proceeding with subsequent study tasks, the 3D tire model was validated.

\section{Ogden material model validation}

The ability of the Ogden material model to accurately reflect the physical properties of the tread was validated by comparing stress-strain relationships derived analytically from the Ogden material model and empirically from the indoor driving tests. Figure 6A shows a high level of agreement between the analytical and empirical results, confirming the adequacy the Ogden material model.
A) Design parameter locations

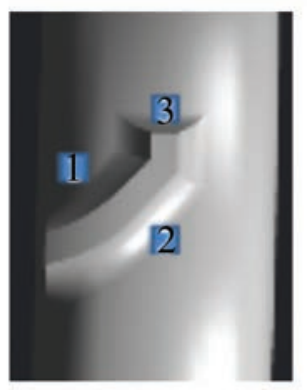

B) Block angle and round

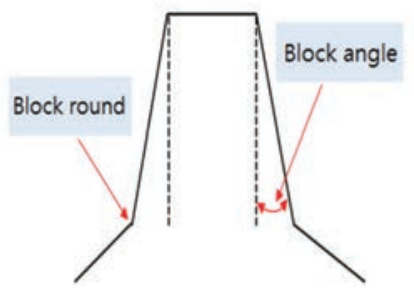

Figure 4. Tread block measurement locations (A and B) for sensitivity analysis.

Table 5. Generated stress for each of the central composite experimental design scenarios.

\begin{tabular}{lcccc} 
Scenario & \multicolumn{3}{c}{$\begin{array}{c}\text { Design } \\
\text { variable } \\
\text { DV } 4\end{array}$} & $D V_{6}$ \\
\hline 1 & 10 & 10 & 10 & 2.5621 \\
2 & 40 & 10 & 10 & 1.9513 \\
\hline 3 & 10 & 40 & 10 & 2.3216 \\
4 & 40 & 40 & 10 & 2.1478 \\
\hline 5 & 10 & 10 & 40 & 2.2254 \\
6 & 40 & 10 & 40 & 1.8571 \\
\hline 7 & 10 & 40 & 40 & 2.1234 \\
8 & 40 & 40 & 40 & 1.5251 \\
\hline 9 & 6.76 & 25 & 25 & 2.8151 \\
10 & 43.24 & 25 & 25 & 1.5315 \\
\hline 11 & 25 & 6.76 & 25 & 1.98315 \\
12 & 25 & 43.24 & 25 & 1.8432 \\
\hline 13 & 25 & 25 & 6.76 & 1.8315 \\
14 & 25 & 25 & 43.24 & 1.8532 \\
\hline 15 & 25 & 25 & 25 & 1.8839 \\
\hline
\end{tabular}

Table 6. Design variable values and generated stress before and after optimisation.

\begin{tabular}{lccc} 
Factor & $\begin{array}{c}\text { Before } \\
\text { optimisation }\end{array}$ & $\begin{array}{c}\text { After } \\
\text { optimisation }\end{array}$ & $\begin{array}{c}\text { Percent } \\
\text { change }\end{array}$ \\
$D V_{2}$ & 25 & 38.26 & \\
$D V_{4}$ & 25 & 35.87 & \\
\hline$D V_{6}$ & 25 & 39.92 & \\
Von Mises stress (MPa) & 1.89 & 1.57 & $-16 \%$ \\
\hline
\end{tabular}

Table 7. Time until cracking before and after optimisation.

\begin{tabular}{lccc} 
Factor & $\begin{array}{c}\text { Before } \\
\text { optimisation }\end{array}$ & $\begin{array}{c}\text { After } \\
\text { optimisation }\end{array}$ & $\begin{array}{c}\text { Percent } \\
\text { change }\end{array}$ \\
Time until cracking (h) & $\begin{array}{c}568 \\
\text { (see Figure 5C) }\end{array}$ & $\begin{array}{c}784 \\
\text { (see Figure 5D) }\end{array}$ & $+38 \%$ \\
\hline
\end{tabular}




\section{Tire deformation}

Under an applied vehicle load, the entire tire deforms at the tireroad surface interface (Witzel and Bottinger, 2011). To validate the ability of FEM model in this study to replicate this phenomenon, the tire footprint produced from the FEM model and based on experimental input data was compared with a tire footprint observed in practice. Figure $6 \mathrm{~B}$ shows this comparison. The similar size and shape of the two footprints confirm the adequacy of the FEM model in replicating the tread deformation phenomenon.

\section{Generated stress}

While supporting a vehicle load, tires also rotate. The resultant forces from the combined loading and rotation deform the tread and generate stress at the point of deformation. Figure 6C shows the generated stress under combined loading and rotation as estimated by the FEM model used in this study. The highest stress was observed in areas of tread deformation. Confirming the adequacy of the ability of the FEM model to estimate generated stress in a tire, this finding was consistent with the results of the indoor driving tests that indicated cracking in the areas of tread deformation.

\section{Tread design optimisation}

\section{Sensitivity analysis}

As noted previously, the number of design variables considered for tread optimisation was reduced to three based on the sensitivity analysis results. The design variables representing the tread block rounds $\left(D V_{2}, D V_{4}\right.$, and $\left.D V_{6}\right)$ exhibited the highest sensitivities and were thus subsequently considered for tread optimisation.

\section{A) Driving test failure}

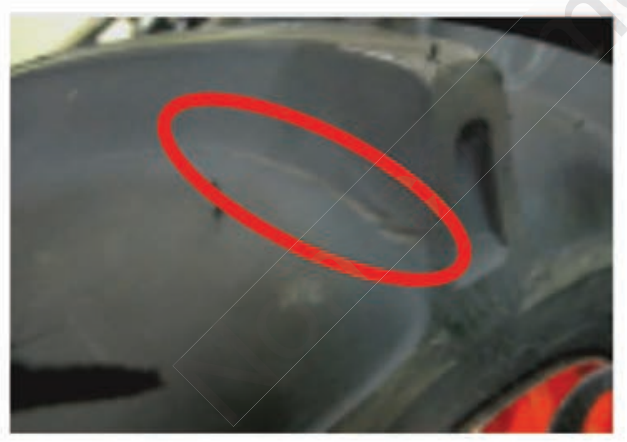

\section{C) Before optimisation}

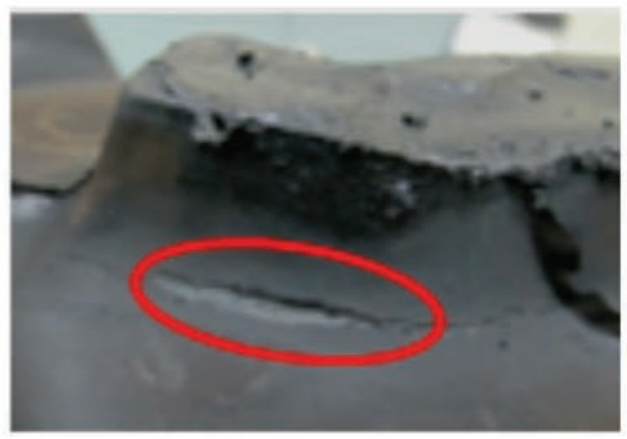

\section{Optimisation}

Figure 7 depicts the tire tread design before and after optimisation. Table 5 lists the generated stress for each of the central composite experimental design scenarios estimated through tire rotation analysis. Table 6 compares the design variable values and generated stress for a conventional agricultural lug tire and a tire with the optimised tread design. Results indicated that the optimised tread design decreased tire tread stress by $16 \%$ compared with conventional agricultural lug tires.

\section{Tread design validation}

The purpose of this study is to increase the life of tread roots. Therefore, only the cracking time at the root was confirmed from the optimisation process. As a final task in this study, we evaluated the durability of the optimised tread design using a tire prototype. As shown in Table 7 (and Figure 5C and D), results indicated that the optimised tread design increased the time until cracking by $38 \%$ (784 vs 568 h) compared with conventional agricultural lug tires.

\section{Conclusions}

In this study, we optimised and validated a tread design for agricultural lug tires intended to reduce the generated stress and increase the durability of a tire using failure analysis. Specifically, we identified tire failure modes using indoor driving tests and FMEA. Next, we developed a 3D tire model using the Ogden material model and FEM. Using sensitivity analysis and RSM, we optimised the tread design. Finally, we evaluated the durability of

\section{B) In-practice failure}

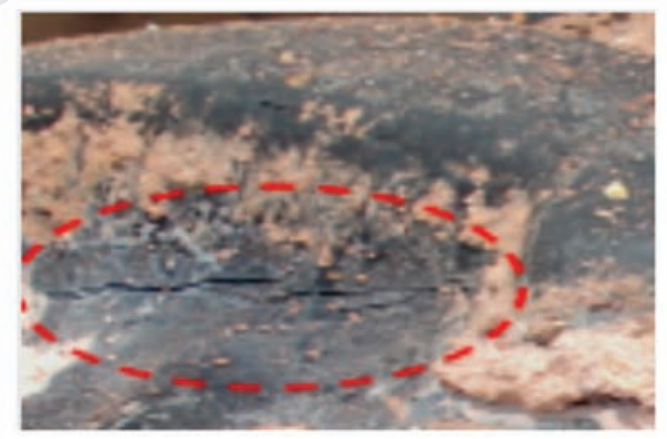

D) After optimisation

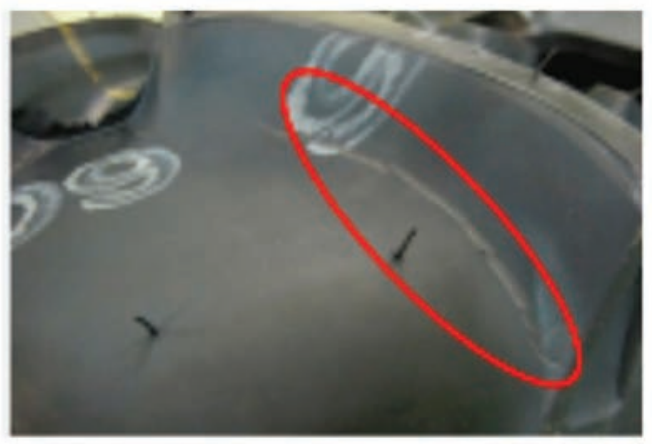

Figure 5. Tire failures observed during A) driving tests and B) in-practice test; time until cracking C) before and D) after optimisation. 
A) Stress-strain curve comparison from Ogden model and test data

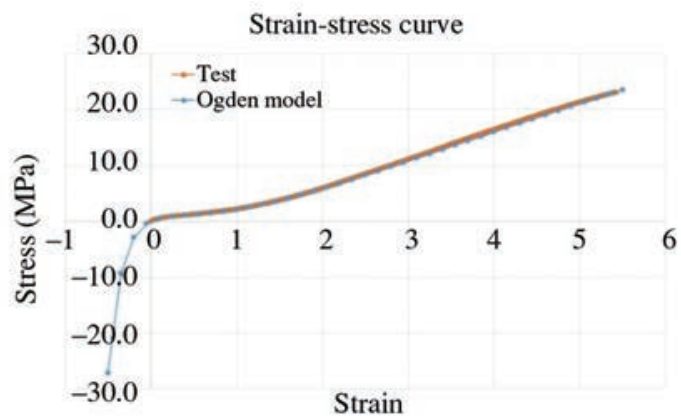

B) Tire footprint by In-practice and FEM model

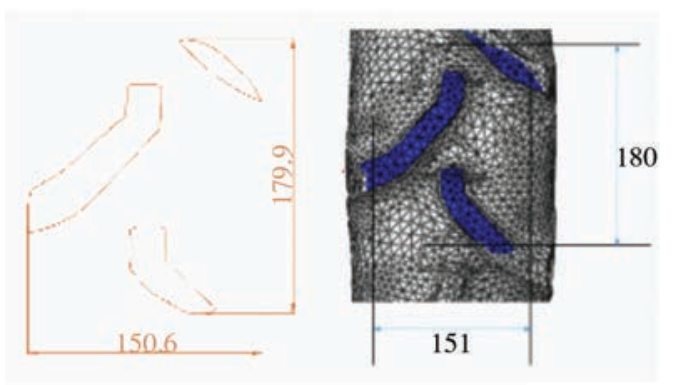

C) Generated stress estimated by the FEM model

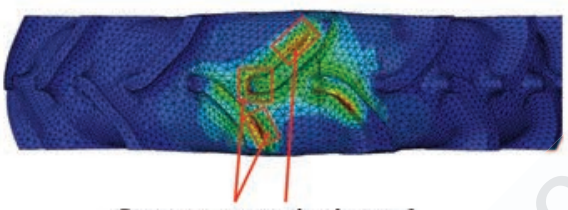

Stress concentration in tread

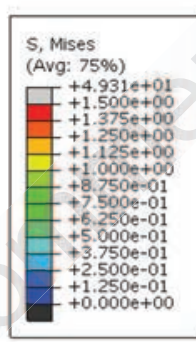

Figure 6. A-C) Material characteristics and pressured characteristics of the tread.

the new design using a tire prototype and drum test equipment.
A) Before optimisation

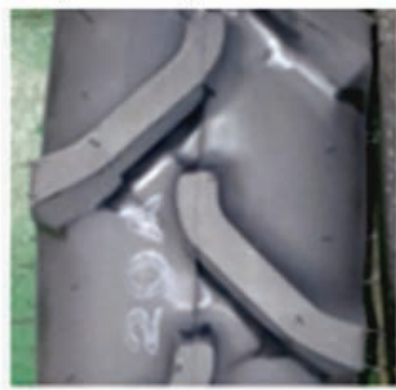

B) After optimisation

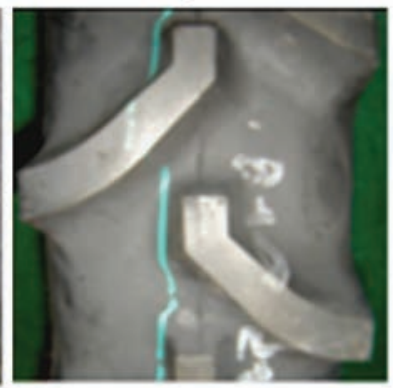

Figure 7. Tires tread design A) before and B) after optimisation.
Sensitivity analysis identified the tread block rounds as influential design factors. Subsequent analytical and empirical results indicated that the optimised tread design decreased the tire tread stress by $16 \%$ and increased its time until cracking by $38 \%$ compared to conventional agricultural lug tires.

The results of this study substantially contribute to the understanding of tire failure modes and optimum tread designs. In addition, the results of this research can be directly applied to improve the design of agricultural lug tires and subsequently prevent unexpected tire failures.

Future research will be carried out to improve the service life due to tire wear and load variation.

\section{Nomenclature}

$\alpha_{p}$ : material constant;

$\beta$ : coefficients estimated using least squares method;

$\lambda$ : stretch ratio (initial/post-tension length of the material);

$\mu_{p}$ : material constant;

$D V$ : design variable;

$X$ : experimental data matrix;

$Y$ : analytical data matrix;

$W$ : tensile strength of a rubber material;

$y$ : maximum stress measured at tire tread.

\section{References}

Bailey A.C., Raper R.L., Way T.R., Burt E.C., Johnson C.E. 1996. Soil stresses under a tractor tire at various loads and inflation pressures. J. Terramech. 33:1-11.

Bas D., Boyaci I.H. 2007. Modelling and optimisation I: usability of response surface methodology. J. Food Eng. 78:836-45.

Bezerra M.A., Santelli R.E., Oliveira E.P., Villar L.S., Escaleira L.A. 2008. Response surface methodology as a tool for optimisation in analytical chemistry. Talanta. 76:965-77.

Biris S.S., Ungureanu N., Maican E., Murad E., Vladut V. 2011. FEM model to study the influence of tire pressure on agricultural tractor wheel deformations. pp 223-228 in Proc. $10^{\text {th }}$ Int. Sci. Conf.: Eng. Rural Dev., Jelgava, Latvia.

Box G.E.P., Wilson K.B. 1951. On the experimental attainment of optimum conditions. J. R. Stat. Soc. Series B. 13:1-45.

Box G.E.P., Draper N.R. 1987. Empirical model building and response surfaces. John Wiley and Sons, New York, NY, USA, pp 143-167.

Choi J.H., Kang N.C. 2015. Run-flat tire optimisation using response surface method and genetic algorithm, Trans. Korean Soc. Noise Vib. 25:247-54.

Craig K.J., Stander N., Dooge D.A., Varadappa, S. 2005. Automotive crashworthiness design using response surfacebased variable screening and optimisation. Eng. Computation. 22:38-61.

Mohsenimanesh A., Ward S.M., Gilchrist M.D. 2009. Stress analysis of a multi-laminated tractor tyre using non-linear 3D finite element analysis. Mater. Des. 30:1124-32.

Nankali N., Namjoo N., Maleki M.R. 2012. Stress analysis of tractor tire interacting with soil using 2D finite element method. Int. J. Adv. Des. Manuf Tech. 5:107-11.

Ogden R.W. 1984. Non-linear elastic deformations. Halsted Press, Chichester, NY, USA, pp 169-229.

Olmstead T., Fischer E. 2009. Estimating vertical stress on soil subjected to vehicular loading. U. S. Army Corps of Engineers, Engineer Research and Development Center/Cold Region 
Research and Engineering Laboratory, Hanover, NH, USA. ERDC/CRREL TR-09-2: 1-29. Available from: http://digitalcommons.unl.edu/cgi/viewcontent.cgi?article=1044\&context=usarmyresearch

Rausand M., Hoyland A. 2004. System reliability theory - Models, statistical methods and applications, second edition. John Wiley and Sons, Inc., Publication, New York, NY, USA. Available from: https://notendur.hi.is/hthb1/Áreiðanleiki\%20kerfa/ System\%20Reliability\%20Theory\%20Models\%20and\%20Sta tistical\%20Methods.pdf
Roth J., M. J. Darr M.J. 2012. Measurement of normal stresses at the soil-tire interface. Biol. Eng. Trans. 55:325-31.

Roux W.J., Preez R.J., Stander N. 1999. Design optimisation of a semi-solid tyre using response surface approximations. Eng. Computation. 16:165-84.

Way T.R., Kishimoto T., Torbert H.A., Burt E.C., Bailey A.C. 2009. Tractor tire aspect ratio effects on soil bulk density and cone index. J. Terramech. 46:27-34.

Witzel P., Bottinger S. 2011. Upgrading of the Hohenheim tyre model to a radial approach. 